\title{
Development of Leptospira Killed Whole Culture Vaccine Using Different Adjuvants and Evaluation of Humoral Immune Response in Hamsters
} \author{
Ghaderi², G. shokri $^{2}$ \\ ${ }^{1}$ Immunology Research Center, Tabriz University of Medical Sciences, Tabriz, Iran \\ ${ }^{2}$ Razi Vaccine and Serum research Institute, Karaj, Iran \\ ${ }^{3}$ Department of Immunology, Faculty of Medicine, Tabriz University of Medical Sciences, Tabriz, Iran \\ ${ }^{4}$ Tehran Medical University, Tehran, Iran \\ ${ }^{5}$ Department of Immunology, Faculty of Medicine Tarbiat Modares University, Tehran, Iran
}

R. Banihashemi ${ }^{1,2,5}$, B. Baradaran ${ }^{1,3}$, M. Tebianian ${ }^{2}$, J. Majidi $^{1,3}$, A. Jabbari² ${ }^{2}$ S. Jalali ${ }^{4}$, H.mohammadpour ${ }^{5}$, K. Tadayyon $^{2}$, M. Sekhavati $^{2}$, R. $^{2}$

\begin{abstract}
Leptospirosis is an acute infectious disease caused by Leptospira spp. that produces a broad range of health problems mainly in developing world. In several affected countries, a major attempt has been begun to find a potent and effective vaccine. This is while; the available vaccines neither perused immunological memory nor confer cross-protection. Four-week-old male hamsters were subcutaneously inoculated with four-leptospiral vaccine and four-control adjuvant through a triple-injection regiment at fortnightly intervals. Animals were bled through the saphenous vein weekly until the seventh week. We have demonstrated that adjuvant plays a fundamental role in the type and extent of the immune responses raised by leptospiral vaccination. We strongly recommend selection of alum in any formulation of leptospiral vaccine.
\end{abstract}

Keywords: Leptospirosis; Vaccine; Adjuvant; Immune responses; Humoral immunity

\section{Introduction}

Leptospirosis is an infectious disease caused by pathogenic bacteria genus Leptospira. This bacterium could be transmitted from animals to humans. Leptospirosis in humans can cause mild and acute form of the disease. Mild leptospirosis symptoms are similar to influenza disease and acute form symptoms are similar to hepatitis and renal failure. Except certain circumstances, the bacteria are difficult to grow in a normal environment. In several affected countries, a major attempt has been begun to find a potent and effective vaccine. This is while; the available vaccines neither perused immunological memory nor confer cross-protection [1-5]. Nowadays the available commercial animal vaccines currently used worldwide are killed, whole-cell vaccines [6]. Adjuvant free form of this vaccine may fail to prevent renal shedding in infected animals [7]. Aluminum based adjuvant have been used for decades and their value in immunization plan is striking, their ability to activate strong humoral immunity $[8,9]$. Meanwhile, the oil adjuvant vaccine industry has an important role. Leptospira can stimulate several mechanisms of immune responses. Innate immunity is the first line of defense against Leptospira ${ }^{\circ}$. Complement system also plays an important role in defense against Leptospira [10]. Mechanism of resistance against leptospira infection was thought to be primarily humoral response, although recent studies pointed to a role for cellmediated immunity [11]. In this study, modified media were used for bacterial growth and vaccine preparation. The purpose of our study is, investigation the effects of different adjuvants on the induction of humoral immunity in laboratory animal hamster and find the best formulation for this vaccine [12].

\section{Materials and Methods}

\section{Leptospira strains}

The virulent Leptospira interrogans serovar canicola, sejroe hardjo and grippotyphosa were obtained from Razi vaccine and serum research institute (RVSRI), Karaj, Iran.

\section{Leptospira culture}

This method was developed in RVSRI and all materials used were obtained from Merck Company (Germany). Leptospira was cultivated in low protein chemical media. Hence, the salt solution was autoclaved. Then, another solution consisted of TPB (Triptose Phosphate Broth), yeast, beef extract, vitamin B12 and thiamine (vitamin B1), Tween 80, BSA (Bovine Serum Albumin), sodium pyrovate and SOD (Superoxide Dismutase) undergone filtration $(0.25 \mu \mathrm{m})$ and complete homogenization, was added. All different leptospira serovars have been cultured at $29^{\circ} \mathrm{C}$ aerobically in similar conditions. Turbidimetry method was used to evaluate the rate of bacterial growth.

\section{Vaccines preparation}

The three different L. interrogans serovars (serovar sejroe hardjo, grippotyphosa, and canicola) were cultured in the media, and then inactivated by formalin at the final concentration of $0.4 \%$. The whole cells of each leptospira serovars cultures were separated by centrifugation at 12,000 RPM for $30 \mathrm{~min}$. The supernatants were discarded, and thin pellets were suspended in $0.9 \%$ sodium chloride solutions. In order to prepare the trivalent vaccine, the density of each suspension of respective serovar of the Grippotyphosa, Canicola, and Sejro hardjo was measured, pooled, and mixed in $0.9 \%$ sodium chloride solution (at least $1 \times 10^{9}$ bacteria/ml) [13]. As the adjuvant, $10 \%$ aluminum hydroxide gel, 50\% EDO1 (olive oil) and 50\% EDO2 (olive oil and additives) were added separately and slowly to the mixed bacterial suspension by magnetic stirrer. The four final products were labeled as modified aluminum hydroxide, EDO1, EDO2 oil/water (O/W) adjuvant vaccine and without adjuvant, kept at $4^{\circ} \mathrm{C}$ until use. Sterility and purity tests of this vaccine were done ordinarily.

*Corresponding author: Reza Banihashemi, Ph.D Student of Medical Immu nology, Alborz, Kraj, Hesarak, Beheshti Blv, Razi Vaccine Serum Research Institute, Postal code: 3197619751, Iran, Tel: +98- 26-345-027-49; 989-126134-324; E-mail: Reza7471@gmail.com

Received March 10, 2013; Accepted April 26, 2013; Published May 28, 2013 Citation: Banihashemi R (2013) Development of Leptospira Killed Whole Culture Vaccine Using Different Adjuvants and Evaluation of Humoral Immune Response in Hamsters. J Vaccines Vaccin 4: 185. doi:10.4172/2157-7560.1000185

Copyright: @ 2013 Banihashemi R. This is an open-access article distributed unde the terms of the Creative Commons Attribution License, which permits unrestricted use, distribution, and reproduction in any medium, provided the original author and source are credited. 
Citation: Banihashemi R (2013) Development of Leptospira Killed Whole Culture Vaccine Using Different Adjuvants and Evaluation of Humoral Immune Response in Hamsters. J Vaccines Vaccin 4: 185. doi:10.4172/2157-7560.1000185

Page 2 of 5

\section{Laboratory animals}

Total 40 healthy Balb/c mice, 40 healthy white male New Zealand rabbits, 40 healthy white guinea pigs and 104 healthy hamsters were delivered from Animal Production Department and housed distinctly under clean similar conditions. All animals were fed ad libitum (Tables 1 and 2) $[14,15]$.

\section{Safety trials}

Safety trial for each vaccine, 5 mice, 5 rabbits, 5 hamsters, and 5 guinea pigs, each received the vaccine intra peritoneal (IP) and 5 mice, 5 rabbits, 5 hamsters, and 5 guinea pigs, subcutaneously. The inoculation dose for mice was $0.5 \mathrm{ml}$ and for others were $2 \mathrm{ml}$. All the animals were observed 14 days for any contrary or reverse reaction attributable to the vaccination (Table 2). All of the animals were observed at least $3 \mathrm{~h}$ post vaccination for any sign of possible anaphylactic reaction. The Booster dose was given 3 months later to every animal and also monitored for $2 \mathrm{~h}$ for any anaphylactic reactions. The animals were also examined daily for any local reactions at the inoculation site and death up to 1 week [14].

\section{Immunization}

Hamsters were divided into eight groups. Animals were immunized subcutaneously with $1 \mathrm{ml}$ of each vaccine and boosted 2 times, the first time after two weeks and the second time 3 weeks later ( 5 weeks after first inoculation) with the same dose $[16,17]$. Animals were bled through the saphenous vein weekly until the seventh week and sera were collected and kept at $-80^{\circ} \mathrm{C}$ until use [9].

\section{Evaluation of antibody response by ELISA}

The antibody responses against various vaccine preparations were evaluated by the Enzyme- Linked Immunosorbent Assay as had been described previously by Faisal et al. [9] and Chang et al. [18].

Briefly, the wells of polystyrene plates (Nunc) were coated with $100 \mu \mathrm{l}$ of antigens $\left(10^{9}\right.$ Leptospira boiled in carbonate buffer, 0.1 M, pH 9.6) [19]. The plate was washed three times with $0.1 \mathrm{M}$ PBS containing $0.05 \%$ Tween 20 (PBST) and then blocked with $200 \mu \mathrm{l} /$ well of $1 \%$ BSA for $2 \mathrm{~h}$ at room temperature. After the usual washing steps, $100 \mu$ of hamster serum (control and vaccinated) diluted 1:100 in PBST was added to each well and incubated for $1 \mathrm{~h}$ at $37^{\circ} \mathrm{C}$ in a humid chamber. The plate was washed three times with PBST and incubated with $100 \mu \mathrm{l}$ of a 1:2000 dilution of goat antihamster IgG conjugated to horseradish peroxides (ABcam) for $30 \mathrm{~min}$ at room temperature. After five times washing with PBST, $100 \mu \mathrm{l}$ of Tetra Methyl Benzidine (Sigma) was added to each well. The plate was read five times at $30 \mathrm{sec}$ intervals at $650 \mathrm{~nm}$ On ELISA reader (BIO-Rad, USA) [20].

\section{Statistics}

Statistical significance was determined by Anowa test using STATA soft ware. $\mathrm{P}<0.05$ values were considered statistically significant.

\section{Results}

\section{Vaccine safety}

According to our safety tests results, neither anaphylactic shock reaction nor noticeable local inflammations were detected in the

\begin{tabular}{|c|c|c|}
\hline Vaccine & Animal & Dose \\
\hline Vaccine & 8 & $1 \mathrm{cc}$ \\
\hline Vaccine +Alum & 8 & $1 \mathrm{cc}$ \\
\hline Vaccine+EDO1 & 8 & $1 \mathrm{cc}$ \\
\hline Vaccine+EDO2 & 8 & $1 \mathrm{cc}$ \\
\hline Saline normal & 8 & $1 \mathrm{cc}$ \\
\hline Alum & 8 & $1 \mathrm{cc}$ \\
\hline EDO1 & 8 & $1 \mathrm{cc}$ \\
\hline EDO2 & 8 & $1 \mathrm{cc}$ \\
\hline
\end{tabular}

Table 1: Animal immunization schedule.

\begin{tabular}{|l|l|l|l|l|l|}
\hline Animals & Dose & Vaccine & Vaccine+Alum & Vaccine+EDO1 & Vaccine+EDO2 \\
\hline Balb/c mice & $0.5 \mathrm{ml}^{\mathrm{a}}$ & $10 / 10^{\mathrm{b}}$ & $10 / 10^{\mathrm{a}}$ & $10 / 10^{\mathrm{a}}$ & $10 / 10^{\mathrm{a}}$ \\
\hline $\begin{array}{l}\text { New Zealand } \\
\text { rabbits white }\end{array}$ & $2 \mathrm{ml}$ & $10 / 10^{\mathrm{a}}$ & $10 / 10^{\mathrm{a}}$ & $10 / 10^{\mathrm{a}}$ & $10 / 10^{\mathrm{a}}$ \\
\hline $\begin{array}{l}\text { White guinea } \\
\text { pigs }\end{array}$ & $2 \mathrm{ml}$ & $10 / 10^{\mathrm{a}}$ & $10 / 10^{\mathrm{a}}$ & $10 / 10^{\mathrm{a}}$ & $10 / 10^{\mathrm{a}}$ \\
\hline Hamsters & $2 \mathrm{ml}$ & $10 / 10^{\mathrm{a}}$ & $10 / 10^{\mathrm{a}}$ & $10 / 10^{\mathrm{a}}$ & $10 / 10^{\mathrm{a}}$ \\
\hline
\end{tabular}

a 5 mice, 5 rabbits, 5 hamsters, and 5 guinea pigs, each received the vaccine intra peritoneal (IP) and 5 mice,

rabbits, 5 hamsters, and 5 guinea pigs, subcutaneously.

${ }^{\mathrm{b}}$ All animals survived after vaccination

Table 2: Results of safety trials in animals vaccinated with several adjuvant leptospiral vaccine.

laboratory animals during the 14-day observation period (Table 2).

\section{Leptospira vaccine efficacy without adjuvant}

In the view of the results (Figure $1 \mathrm{~A}$ ), we evaluated the protective efficacy of Leptospira vaccine without adjuvant in a sensitive hamster. Results showed slight and significant elevation of antibody titer after immunization compared to control group $(\mathrm{P}<0.05)$. Also antibody titer has been increasing significantly after boosting. The increase in antibody titer after booster injection was higher than other groups, and then the rate of increase was less than in the other groups, in other hand, response to repeated boosting was much lower. In control group, which solely received physiological serum, no noticeable changes were observed.

\section{Leptospira vaccine efficacy with alum adjuvant}

Immunization of Hamester by Leptospira vaccine with alum adjuvant induced highest specific antibody responses followed by relatively high constant antibody level after repeated boosting (Figure 1B). Compared to control group, there has been significant raise in antibody titer in this group $(\mathrm{P}<0.05)$.

\section{Leptospiral vaccine efficacy with EDO1 adjuvant}

Hamster sera were collected after the final immunization and assayed for anti leptospira IgG response by ELISA. Administration of Leptospira vaccine containing EDO1 adjuvant induced a strong antibody response similar to the vaccine prepared by alum adjuvant. Striking point in this group was antibody titer rising in second boosting compared to the other groups (Figure 1C). Like the previously mentioned group, antibody titer in this group was significantly higher than the control group $(\mathrm{P}<0.05)$.

\section{Leptospira vaccine efficacy with EDO2 adjuvant}

Antibodies level against Leptospira vaccine with EDO2 
adjuvant developed in all subjects who received two or more doses proved to be highly different from the control group $(\mathrm{P}<0.05)$. In this group antibody titer elevation was higher and stronger by repeated boosting doses (Figure 1D).

\section{Antibody affinity evaluation by challenging with $L$. Canicola}

According to our data (Figure 1) eight week after challenge by L. canicola in different groups with same placebo, antibody titer was significantly decreased. Antibody decreasing slope in vaccine without adjuvant and vaccine along EDO2 groups was rapid by challenging with acute strain of L. canicola and antibody titer in week 7 slowed down and was equal to week two. On the other hand, antibody decreasing slopes in vaccine with alum and EDO1 were slow and their antibody levels in week seven were equal to week 5 and unchanged respectively after challenging by L. canicola.

\section{Discussion}

Liptosipra pathologic mechanism is a combination of direct damages by the bacteria and the reactions arisen from the host immune system [21]. In recent decades, researchers have found out that both internal and external cellular immune system are capable of being activated as a consequence of Liptosipra infection [22]. To prove it, the researchers studied the amount of IFN releasing from $T$ cells in intracellular immune path and rise in the amount of IgG2, IgG1, $\operatorname{IgE}$ and IgA for cross-cellular [23]. Given the previous researches indicating that both intra- and cross-cellular immune path are involved in the Liptospira immunity of the host, it's clear in designing a more effective vaccine, both immunity paths should taken into account $[11,24]$. In addition, one should recall that most vaccines produced in the world (Japan, Australia, Germany, Denmark, U.S.A) are the killed vaccines treated by temperature or formalin, which lacks enough information available regarding their efficacy [25].

This paper tries to evaluate the immune reactions by Hamster as a lab animal and rising amount of antibody after vaccination [15]. In the recent years, the improvements in the immunization development strategy resulted in much less vaccine side effects as well as adjuvants being more widely used [26]. The transmission systems capability in activating the innate immune systems is accompanied by the transmission of antigen to lymphatic nodes [27,28]. In this respect, implementing remarkable potential of adjuvants like aluminum hydroxide and oil adjuvants are among the pioneers [28,29].

\section{Examining adjuvants and humeral immune system}

A very important mechanism in body immune system defending the Liptospira disease is humeral immune system [30-32]. IgM and IgG anti-bodies can be found in the serum of those who have once exposed to an acute bacteria strain up to 6 years [26]. Antibodies against bacteria lipopolysaccharide (LPS) are the first to fight Liptospira.
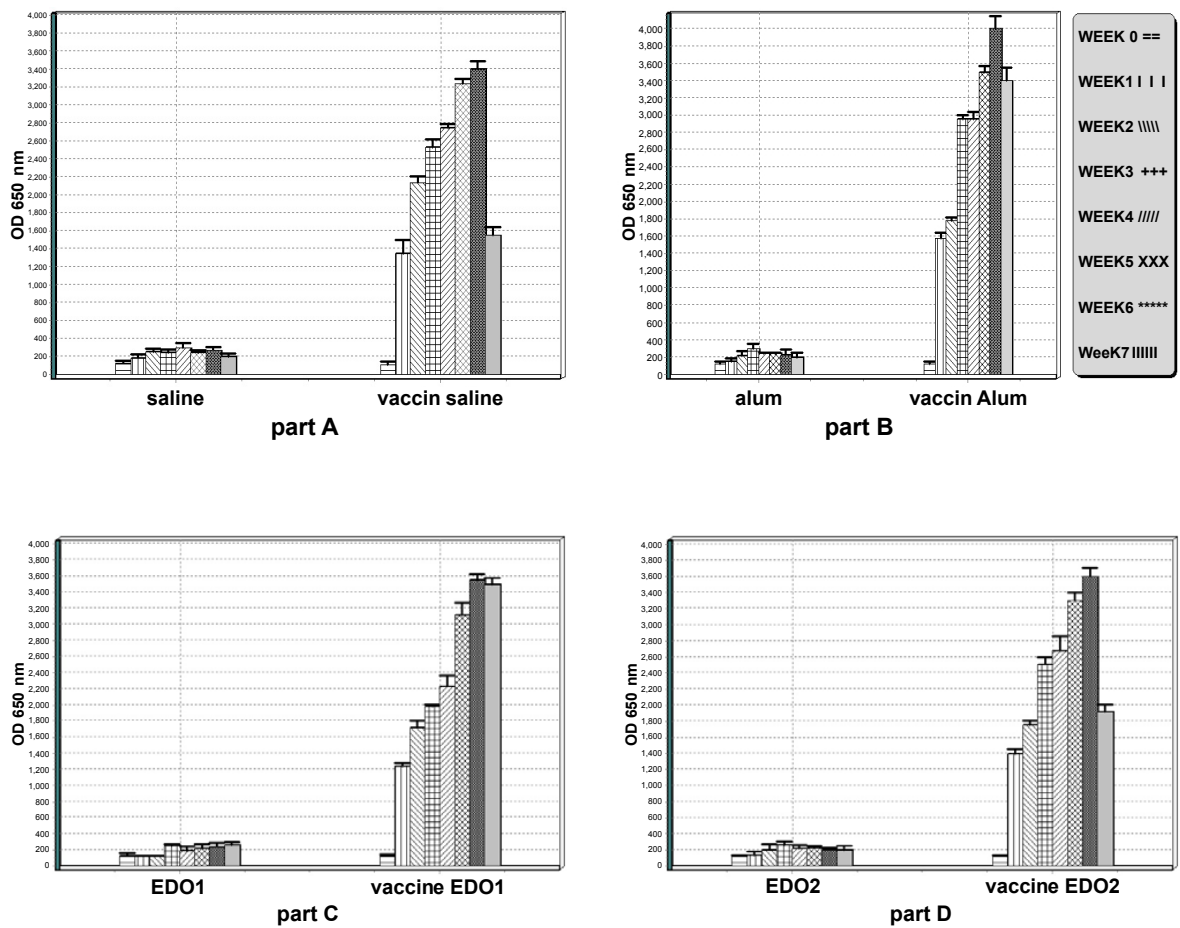

Figure 1: Each column represents the serum antibody within a week. The first column indicates zero weeks and the last column is the seventh week. Part A: Comparison of serum antibodies in the vaccine without adjuvant. Part B: Comparison of serum antibodies in the vaccine with Alum adjuvant. Part C: Comparison of serum antibodies in the vaccine with EDO1 adjuvant. Part D: Comparison of serum antibodies in the vaccine with EDO2 adjuvant. 
Citation: Banihashemi R (2013) Development of Leptospira Killed Whole Culture Vaccine Using Different Adjuvants and Evaluation of Humoral Immune Response in Hamsters. J Vaccines Vaccin 4: 185. doi:10.4172/2157-7560.1000185

Passive immunity in which monoclonal antibodies were used against LPS [32], could manage the establishment of an effective immunity against challenge trials in mice and hamsters [33]. However, there are other antibodies which can be detected due to $\mathrm{Ab}-\mathrm{Ag}$ reactions of immune system to the bacteria's surface proteins that are exposing to immune system of the host, which can play an important role in producing sub-unit vaccines [34]. In this respect, one can refer to OMPH proteins such as OMPL41 and OMPL1 [30].

Studying the elevation of $\mathrm{Ab}$ titres concerning (Figure 1), this paper shows raising antibodies using these vaccines. In comparison, the diagrams show that in first weeks following the first boosting, the antibody levels in the vaccines without adjuvant group were higher than other groups. This increasing might have been resulted from immune system encountering the quick rise in antigen concentration in the host body [35].

Despite the continuous antibody rising in the alum and oil adjuvants group, antibody elevation slope in the vaccine without adjuvant group was inconsistent. Comparing all groups, the highest antibody production levels in the six weeks were observed in the alum group [28]. These data confirmed the gradual antigen releasing of alum and its ability to create local inflammation $[22,36]$. In the present study, the constantivity of the antibody rising after the challenge was investigated. According to the results, after the challenge the minimum antibody declines were related to alum and EDO2 adjuvant vaccines while maximum antibody diminution was associated to vaccine without any adjuvant $[27,29]$. The data showed that the vaccine with alum and EDO2 groups produced active memory cell after vaccination and demonstrated that other groups of vaccine had limited ability to induce memory cell [29].

\section{Adjuvants effects on immune system}

Local inflammation led to summoning up AntigenPresenting Cells (APCs) and to creating the pseudo inflammation [37]. In general, for an efficient priming of adaptive immune responses, presentation of antigen in the context of Major Histocompatibility Complex (MHC) with the induction of accessory signals (costimulators and cytokines) on Antigen-Presenting Cells (APCs) is required [38]. Some adjuvants including alum and oil adjuvants can activate the first signaling and increase the antigen uptake [29]. In contrast to these adjuvant categories, some other adjuvant like the LPS and heat shock protein (HSP) act as co-stimulators [39]. The paper investigated the first category of above-mentioned adjuvants. With rising antigen uptake, these kind of adjuvants intensified the presentation of antigen [37].

In previous researches, the site of injection was sampled and stained to evaluate the inflammation elements after vaccination with alum adjuvant. By day 7 after injection, inflammation with neutrophil, eosinophil and macrophage cells in the injection site was observed. This inflammation could be related to the effect of adjuvant on the antigenpresenting cells $[36,40]$.

In conclusion the study proved the different mentioned adjuvant have appropriate efficacy with Leptospira vaccine especially alum and EDO2 adjuvants. To determine the accurate effect and signaling in these adjuvants, further researches required.

\section{Acknowledgments}

This work was completely financed with the state funds from Razi Vaccine and Serum Research Institute under grant no. 2-18-18-90012. All staff at the Aerobic Bacterial Research and Vaccine Production Department of Razi Institute are thanked for their contribution to conduction of this research. Dr Moazeni Jula and $\mathrm{Dr} \mathrm{H}$ Mohammadpor are much thanked for critically reading and excellent editing the manuscript. Dr J Majidi, a highly respected academician at the Tabriz medical University, He will be missed by all his colleagues and friends. This work was performed under the auspices of the Razi Vaccine and Serum Research Institute (RVSRI) of Iran.

\section{References}

1. Pappas G, Cascio A (2006) Optimal treatment of leptospirosis: queries and projections. Int J Antimicrob Agents 28: 491-496.

2. Zuerner RL, Alt DP, Palmer MV (2012) Development of chronic and acute golden Syrian hamster infection models with Leptospira borgpetersenii serovar Hardjo. Vet Pathol 49: 403-411.

3. Bey RF, Johnson RC (1982) Immunogenicity and humoral and cell-mediated immune responses to leptospiral whole cell, outer envelope, and protoplasmic cylinder vaccines in hamsters and dogs. Am J Vet Res 43: 835-840.

4. Fraga TR, Barbosa AS, Isaac L (2011) Leptospirosis: aspects of innate immunity, immunopathogenesis and immune evasion from the complement system. Scand J Immunol 73: 408-419.

5. (1999) Leptospirosis, Australia, January 1998-March 1999. Wkly Epidemio Rec 74: 113-118.

6. Suepaul SM, Carrington CV, Campbell M, Borde G, Adesiyun AA (2010) Study on the efficacy of Leptospira vaccines developed from serovars isolated from Trinidad and comparison with commercial vaccines using a hamster model Vaccine 28: 5421-5426.

7. Sonrier C, Branger C, Michel V, Ruvoen-Clouet N, Ganiere JP, et al. (2000) Evidence of cross-protection within Leptospira interrogans in an experimental model. Vaccine 19: 86-94.

8. Yan W, Faisal SM, McDonough SP, Divers TJ, Barr SC, et al. (2009) Immunogenicity and protective efficacy of recombinant Leptospira immunoglobulin-like protein $\mathrm{B}(\mathrm{rLigB})$ in a hamster challenge model. Microbes Infect 11: 230-237.

9. Faisal SM, Yan W, McDonough SP, Mohammed HO, Divers TJ, et al. (2009) Immune response and prophylactic efficacy of smegmosomes in a hamster model of leptospirosis. Vaccine 27: 6129-6136.

10. Fraga T, Barbosa A, Isaac $L$ (2011) Leptospirosis: aspects of innate immunity, immunopathogenesis and immune evasion from the complement system. Scand J Immunol 73: 408-419.

11. Adler B, Faine S (1977) Host immunological mechanisms in the resistance of mice to leptospiral infections. Infect Immun 17: 67-72.

12. Silva EF, Santos CS, Athanazio DA, Seyffert N, Seixas FK, et al. (2008) Characterization of virulence of Leptospira isolates in a hamster model. Vaccine 26: 3892-3896.

13. Moazenijula G, Jabbari A, Geravand MM, Banihashemi R, Hajizadeh A (2011) Improvement of trivalent leptospira vaccine by removal of anaphylactic agents. Trop Anim Health Prod 43: 1471-1474.

14. Oie (2010) World organization of animal health.

15. Haake DA (2006) Hamster model of leptospirosis. Curr Protoc Microbiol

16. Zivcec M, Safronetz D, Haddock E, Feldmann H, Ebihara H (2011) Validation of assays to monitor immune responses in the Syrian golden hamster (Mesocricetus auratus). J Immunol Methods 368: 24-35.

17. Evangelista KV, Coburn J (2010) Leptospira as an emerging pathogen: a review of its biology, pathogenesis and host immune responses. Future Microbiol 5 1413-1425.

18. Chang YF, Chen CS, Palaniappan RU, He H, McDonough SP, et al. (2007) 
Citation: Banihashemi R (2013) Development of Leptospira Killed Whole Culture Vaccine Using Different Adjuvants and Evaluation of Humoral Immune Response in Hamsters. J Vaccines Vaccin 4: 185. doi:10.4172/2157-7560.1000185

Page 5 of 5

Immunogenicity of the recombinant leptospiral putative outer membrane proteins as vaccine candidates. Vaccine 25: 8190-8197.

19. Levett PN, Branch SL (2002) Evaluation of two enzyme-linked immunosorbent assay methods for detection of immunoglobulin $M$ antibodies in acute leptospirosis. Am J Trop Med Hyg 66: 745-748.

20. Terpstra W (2003) Human leptospirosis: guidance for diagnosis, surveillance and control: World Health Organization.

21. Mogensen TH (2009) Pathogen recognition and inflammatory signaling in innate immune defenses. Clinical Microbiol Rev 22: 240-273.

22. Baldwin CL, Sathiyaseelan T, Naiman B, White AM, Brown R, et al. (2002) Activation of bovine peripheral blood gammadelta $T$ cells for cell division and IFN-gamma production. Vet Immunol Immunopathol 87: 251-259.

23. Lingappa J, Kuffner T, Tappero J, Whitworth W, Mize A, et al. (2004) HLA-DQ6 and ingestion of contaminated water: possible gene-environment interaction in an outbreak of Leptospirosis. Genes Immun 5: 197-202.

24. Faine S (1994) Leptospira and leptospirosis: CRC Press Inc.

25. Martínez R, Pérez A, Quiñones MC, Cruz R, Álvarez Á, et al. (2004) Efficacy and safety of a vaccine against human leptospirosis in Cuba. Rev Panam Salud Publica 15: 249-255

26. Jost BH, Adler B, Vinh T, Faine S (1986) A monoclonal antibody reacting with a determinant on leptospiral lipopolysaccharide protects guinea pigs against leptospirosis. J Med Microbiol 22: 269-275.

27. Schnare M, Barton GM, Holt AC, Takeda K, Akira S, et al. (2001) Toll-like receptors control activation of adaptive immune responses. Nat Immunol 2 : 947-950.

28. Vecchi S, Bufali S, Skibinski DA, O'Hagan DT, Singh M (2012) Aluminum adjuvant dose guidelines in vaccine formulation for preclinical evaluations. J Pharm Sci 101: 17-20.

29. Ulanova M, Tarkowski A, Hahn-Zoric M, Hanson LA (2001) The common vaccine adjuvant aluminum hydroxide up-regulates accessory properties of human monocytes via an interleukin-4-dependent mechanism. Infect Immun 69: $1151-1159$

30. Guerreiro H, Croda J, Flannery B, Mazel M, Matsunaga J, et al. (2001)
Leptospiral proteins recognized during the humoral immune response to leptospirosis in humans. Infect Immun 69: 4958-4968.

31. Rogers AN, VanBuren DG, Hedblom E, Tilahun ME, Telfer JC, et al. (2005) Function of ruminant gammadelta T cells is defined by WC1.1 or WC1.2 isoform expression. Vet Immunol Immunopathol 108: 211-217.

32. Cumberland P, Everard CO, Wheeler JG, Levett PN (2001) Persistence of antileptospiral $\operatorname{lgM}$, IgG and agglutinating antibodies in patients presenting with acute febrile illness in Barbados 1979-1989. Eur J Epidemiol 17: 601-608.

33. Dai B, Jiang N, Li S, Fang Z, Zhao H, et al. (1998) [Immunoprotection in guinea pigs using DNA recombinant plasmid rpDJt and expressed protein P68 in L. interrogans serovar lai]. Hua Xi Yi Ke Da Xue Xue Bao 29: 248-251.

34. Palaniappan RU, McDonough SP, Divers TJ, Chen CS, Pan MJ, et al. (2006) Immunoprotection of recombinant leptospiral immunoglobulin-like protein A against Leptospira interrogans serovar Pomona infection. Infect Immun 74: 1745-1750.

35. Rimaniol AC, Gras G, Verdier F, Capel F, Grigoriev VB, et al. (2004) Aluminum hydroxide adjuvant induces macrophage differentiation towards a specialized antigen-presenting cell type. Vaccine 22: 3127-3135.

36. White RG, Coons AH, Connolly JM (1955) Studies on antibody production. IV The role of a wax fraction of Mycobacterium tuberculosis in adjuvant emulsions on the production of antibody to egg albumin. J Exp Med 102: 83-104.

37. Eisenbarth SC, Colegio OR, O'Connor W, Sutterwala FS, Flavell RA (2008) Crucial role for the Nalp3 inflammasome in the immunostimulatory properties of aluminium adjuvants. Nature 453: 1122-1126.

38. Bomford R (1980) The comparative selectivity of adjuvants for humoral and cellmediated immunity. I. Effect on the antibody response to bovine serum albumin and sheep red blood cells of Freund's incomplete and complete adjuvants alhydrogel, Corynebacterium parvum, Bordetella pertussis, muramyl dipeptide and saponin. Clin Exp Immunol 39: 426-434.

39. Yang CW, Hung CC, Wu MS, Tian YC, Chang CT, et al. (2006) Toll-like recepto 2 mediates early inflammation by leptospiral outer membrane proteins in proximal tubule cells. Kidney Int 69: 815-822.

40. Phillpotts RJ, Venugopal K, Brooks T (1996) Immunisation with DNA polynucleotides protects mice against lethal challenge with St. Louis encephalitis virus. Arch Virol 141: 743-749. 